\title{
Effects of Local Cooling Media on the Mechanical Properties of Heat Treated Mild Steel
}

\author{
Adeyinka Adebayo, Joseph T. Stephen, and Gbenga J. Adeyemi
}

\begin{abstract}
This paper reports the effects of local cooling media (groundnut oil, palm oil, shea butter and air) on the mechanical properties of heat treated mild steel. Tensile test, hardness test and microstructural analysis were carried out on the heat treated and as-purchased specimens. The results show significant differences in the mechanical properties of the heat treated specimens. The hardness profile showed higher values for palm oil-cooled, shea butter-cooled, and the groundnut oilcooled specimens in an increasing of order respectively when compared with as-purchased specimen with 194.9 VHN, whereas a decrease in hardness was recorded for the air-cooled specimen. Furthermore, the yield strength and ultimate tensile strength of the heat treated specimens obtained through the tensile test analysis showed an increase in yield strength for the groundnut oil-cooled (464.4 MPa) and the shea butter-cooled (412.9 MPa) specimens, and a decrease in yield strength for the air-cooled (358.3 MPa) and palm oil-cooled (307.7 MPa) specimens when compared with the as-purchased specimens (376.9 MPa). Also, the same trend was observed in the ultimate tensile strength (UTS) of the specimens. In contrast, the ductility improved in air-cooled specimen (40.28) but decreased in the specimen cooled in the media when compared with aspurchased specimens (34.22). Furthermore, microstructural analysis revealed that the groundnut oil-cooled specimens gave a microstructural quality than the other heat treated specimens.
\end{abstract}

Index Terms-Coolant; Mechanical Properties;

\section{INTRODUCTION}

The mechanical properties of a material play a major role in its selection for engineering applications. Steel is an alloy of iron and carbon with percentage of carbon ranges from $0.05-1.5 \%$ depending on the grade of steel [1], [2]. According to Rajan et al. [3], mild steel are those with carbon content ranges between $0.05 \%$ and $0.3 \%$. They are typically soft, ductile and malleable [1]. It good mechanical properties in terms of hardness, work hardening grade, yield strength, ability to hold high impact load and relatively low cost are factors that increase its application for general engineering purposes.

Heat treatment produces certain microstructure and desired mechanical properties [3], [4]. Investigation

Published on April 17, 2018.

A. Adebayo is with the Department of Mechanical Engineering, Faculty of Engineering, Ekiti State University, Ado-Ekiti, Nigeria. (e-mail: yka615@yahoo.com).

J. T. Stephen is with the Department of Mechanical Engineering, Faculty of Engineering, Ekiti State University, Ado-Ekiti, Nigeria. (e-mail: stevejaytee@yahoo.com).

G. J. Adeyemi is with the Department of Mechanical Engineering, Faculty of Engineering, Ekiti State University, Ado-Ekiti, Nigeria. (e-mail: adeyemi4unad@yahoo.com). conducted by Adebayo and Stephen showed that heat treatment improves yield strength, ultimate strength, hardness of the low carbon steel but the ductility decreases [5]. Studies conducted by Fadare et al. [4] and Hassa [6] on ASTM A-36 mild steel also showed that heat treatment influenced the mechanical properties and microstructure of the steel. Furthermore, research by Offor et al. [7] into effects of various quenching media (air, brine and SAE 40 engine oil) on the mechanical properties of intercritically annealed hot-rolled $0.15 \mathrm{wt} \% \mathrm{C}-0.43 \mathrm{wt} \% \mathrm{Mn}$ steel showed that quenching media and higher intercritical annealing temperature improve the strength and hardness properties but decrease the ductility and notch impact properties of the original steel.

A study of the effect of heat treatment on the mechanical properties of a locally available mild steel studs by Ahaneku et al. [8] using different quenchants (air, SAE 40 engine oil, water and furnace) showed that water quenched specimen proved superior to other specimens quenched in air, furnace and oil, with respect to high strength properties, Brinell hardness, toughness and yield point. Mineral oils have been found to show good cooling capacity for the majority of alloy steels [9]. However, it is widely argued they are relatively expensive, toxic and non-biodegradable, thus, they generate negative environmental effects and have unfavourable effects on human health [10]. Consequently, attentions are now focused on cheap, non-toxic and biodegradable polymers (vegetable fatty-based) oils as a replacement the minerals oils, and considerable research studies have been conducted in these area [9]-[11].

Recently, Odusote et al. [10] evaluate the mechanical properties of medium carbon steel quenched in water and palm oil, they concluded that water increased the strength and hardness, but palm oil improved the ductility of the of the steel. Further studies have also been conducted on mild steel and other alloy of steel under operations such as drawn [12] and [13] welding using vegetable fatty based oil. The results have also shown positive effects of these oils on the mechanical properties and microstructural of the steels. Therefore, this present work aims at investigating the effects of local vegetable cooling media (groundnut oil, palm oil, shea butter and air) on the mechanical properties of heat treated mild steel. The responses of mechanical properties of heat treated mild steel to these local cooling media would be evaluated through tensile test, hardness test and microstructural analysis.

\section{MATERIALS AND METHOD}

The materials employed for this project are: mild steel, shea butter oil, palm oil and groundnut oil. The mild steel rod of $12 \mathrm{~mm}$ diameter was sourced from Universal Steel 
(U-steel) Limited, Ikeja, Nigeria and the chemical analysis of the mild steel is shown in Table I. The cooling media (shea butter oil, palm oil and ground nut oil) was sourced from Oja Oba market at Ado-Ekiti, Nigeria.

\section{A. Material Preparation and Heat Treatment}

The mild steel rod was cut into smaller rod rods and machined into standard specimens in accordance with ASTM E-8 specification for tensile specimen as shown in Fig. 1. Ten standard specimens were produced separately for tensile test and hardness test. Two specimens were retained as-purchased and eight specimens were heat treated, after which cooling/quenching took place in air, palm oil, ground nut oil and shea butter oil.
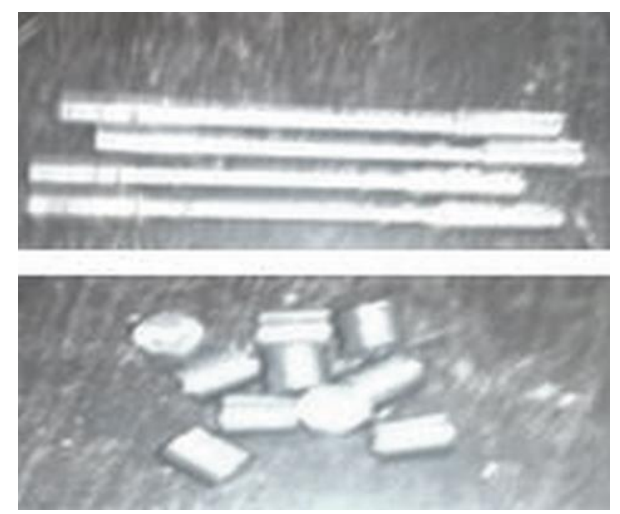

Fig. 1. Stress-strain curve for as-purchased sample, air-cooled sample, groundnut oil-cooled sample, palm oil-cooled sample and shea buttercooled sample

The eight specimens were heat treated to recrystallization temperature $\left(730^{\circ} \mathrm{C}\right)$ in a resistance muffle furnace which has a heating temperature up to $1200^{\circ} \mathrm{C}$. The heating process took approximately one hour. At the recrystallization temperature, the specimens were held (i.e. soaked) for one and a half hours in the furnace in order to attain phase homogeneity. Thereafter, the furnace was switched off, the specimens were then taken out of the furnace and quenched in the media to room temperature. Two of the specimens were allowed to cool in the ordinary environment (i.e. aircooled). Two were quenched directly in palm oil, two in groundnut oil and two in shea butter oil. After about half an hour, the specimens were removed from each of the media and cleaned properly.

\section{B. Mechanical Testing and Microstructure Examination}

The tensile strength properties of both as-purchased and heat treated mild steel specimens were determined using an Instron universal testing machine. The tensile specimens were subjected to Constant Extension Rate Tensile (CERT) tests on the machine. The tensile force versus displacement graph was plotted by the machine as straining continued. The yield strength, ultimate tensile strength and stress at fracture of the specimens were respectively evaluated from the forces indicated where the pointer showed momentary rest after elastic limit before taking off again, at the maximum value of the pointer just before the breaking of the specimen occurred, and at the point of fracture. Finally, the fractured specimen was removed from the grips of the machine and percentage elongation at fracture was obtained by putting the two halves back together and measuring the total stretch in the gauge length.

In compliance with ASTM Standard Hardness Method (ASTM E-92), measurement of hardness properties were carried out on the as-purchased and heat treated specimens. The hardness property was carried out on Vickers microhardness testing machine. A load of $490.3 \mathrm{mN}$ was applied for a dwell period of 10 seconds during the test. For each specimen, an average value of three readings was use to evaluate the hardness.

The microstructural examination was done using an electron microscope. Thereafter, the specimens were washed with water so as to remove any loose grit. The specimens were progressively grinded to obtain a smooth and flat surface polished with emery cloth in decreasing coarseness attached to a rotating disc machine. Thereafter, the specimens were washed with water so as to remove any loose grit. Diamond paste was then used to polish the surface until a mirror-finish appearance was obtained. The polished specimens were then covered with cotton wool and placed in a desiccator to prevent corrosion from the environment. Etching was done with cotton wool and Nital ( $2 \%$ of nitric acid and $9 \%$ of ethanol) to reveal the microstructure of the surface layer. The surface of the specimens were swabbed for 4 seconds and then rinsed under running water. Methylated spirit was used to remove water from the surface and then dried in warm air. The current phase of the specimens were then viewed and photographically recorded with magnifications of 500 with the aid of the electron microscope.

\section{RESULTS AND DISCUSSION}

The stress-strain curves of the tensile test carried out on each specimen were plotted using results obtained from the Instron universal testing machine. Fig. 2 shows the stressstrain curves (on a single graph) obtained from the Instron universal testing machine on the tensile test carried out on each of the specimen. From the stress-strain curves, the air cooled specimen was observed to have the highest strain value per point on the graph, which might be due to the slower cooling rate of specimen in air.

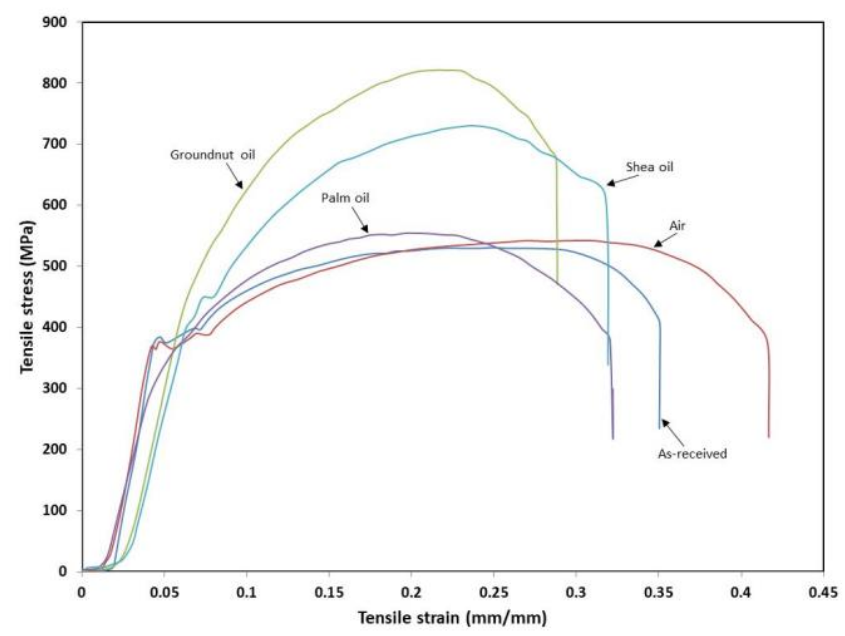

Fig. 2. Stress-strain curve for as-purchased sample, air-cooled sample, groundnut oil-cooled sample, palm oil-cooled sample and shea buttercooled sample. 
TABLE I: CHEMICAL COMPOSITION OF MILD STEEL

\begin{tabular}{lllllllll}
\hline \hline Element & $\mathrm{C}$ & $\mathrm{Si}$ & $\mathrm{Mn}$ & $\mathrm{S}$ & $\mathrm{Cu}$ & $\mathrm{Cr}$ & $\mathrm{Fe}$ & $\mathrm{Others}$ \\
\hline Composition (\%) & 0.2320 & 0.2360 & 0.8030 & 0.0535 & 0.1080 & 0.0805 & 98.3515 & 0.1355 \\
\hline \hline
\end{tabular}

In order to determine the responses of the specimens to tensile tests, values of yield strength $(\sigma y)$, ultimate tensile strength $(\sigma \mathrm{u})$, and percentage elongation at fracture were evaluated from the stress-strain curves and plotted against the different cooling media used. The results are depicted in Table II and Fig. 3 to 6. From the table and figures, it can be observed that cooling the heated mild steel specimens in the different media have varying effects on hardness, strengths and percentage elongations of the specimens.

TABLE II: TREATMENT EFFECTS ON MECHANICAL PROPERTIES OF MILD STEEL COOLED IN DIFFERENT MEDIA

\begin{tabular}{lllll}
\hline \hline Cooling Media & $\begin{array}{l}\text { Hardness } \\
(\text { VHN) }\end{array}$ & $\begin{array}{l}\text { Yield } \\
\text { Strength, } \\
\sigma_{\mathrm{y}}(\mathrm{MPa})\end{array}$ & $\begin{array}{l}\text { Ultimate } \\
\text { Tensile } \\
\text { Strength, } \\
\sigma_{\mathrm{U}}(\mathrm{MPa})\end{array}$ & $\begin{array}{l}\text { Percentage } \\
\text { Elongation } \\
(\%)\end{array}$ \\
\hline As-received & 194.9 & 376.9 & 520.0 & 34.22 \\
Air & 139.8 & 358.3 & 516.1 & 40.28 \\
Groundnut Oil & 209.2 & 464.6 & 815.7 & 28.67 \\
Palm Oil & 196.4 & 307.7 & 548.8 & 32.18 \\
Shea Butter & 207.7 & 412.9 & 727.3 & 31.33 \\
\hline \hline
\end{tabular}

Fig. 3 shows the values of the Vickers Hardness Number (VHN) for the as-received specimen and specimens cooled in different cooling media. The average hardness value was plotted against the cooling media using the average values of three readings at different positions from repeated tests on each specimen.

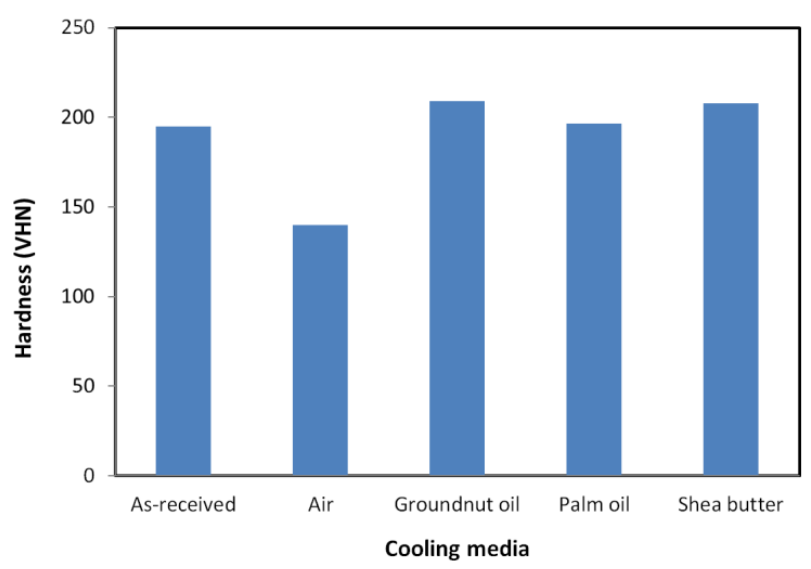

Fig. 3. Hardness of heat treated mild steel cooled in different cooling media.

The measured hardness shows that groundnut oilquenched sample has highest Vickers hardness number (209.2 VHN) compared to other medium-quenched samples, whereas air-cooled sample has the least Vickers hardness. Studies conducted by Adekunle et al [14] on bio-quenching oils reported that rate of heat extraction decreases from melon oil, shea butter oil, palm kernel oil and palm oil. Hence, the recorded hardness values in the present study can be attributed to the cooling rate and viscosity of the cooling media. With the exemption of air, the hardness value of the samples increased after quenching in various media.

It can be seen from the results (Fig. 4) that air-cooled specimen had the highest elongation, followed by the asreceived and shea butter cooled specimens, respectively.
This can be attributed to the low cooling rate of these specimens in these media, as elongation tends to increase with gradual/slow cooling rate. This is consistent with the findings of Gündüz and Çapar that quenching in a medium with faster cooling rate tends to have a negative effect on elongation [15]. Therefore, the groundnut-cooled specimen that experienced fastest cooling rate compared to the others has the least percentage elongation at the fracture.

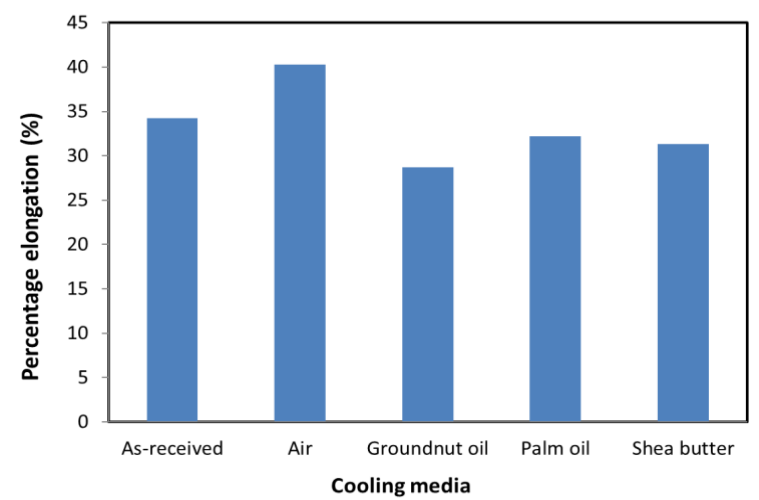

Fig. 4. Percentage elongation of heat treated mild steel cooled in different cooling media.

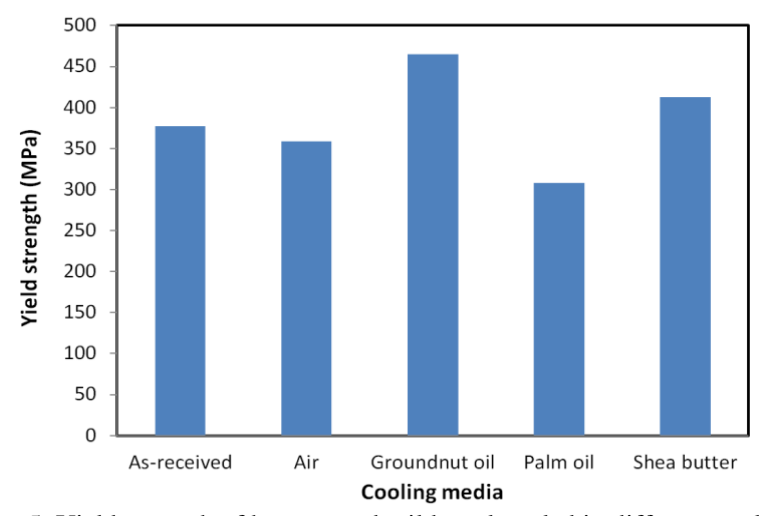

Fig. 5. Yield strength of heat treated mild steel cooled in different cooling media.

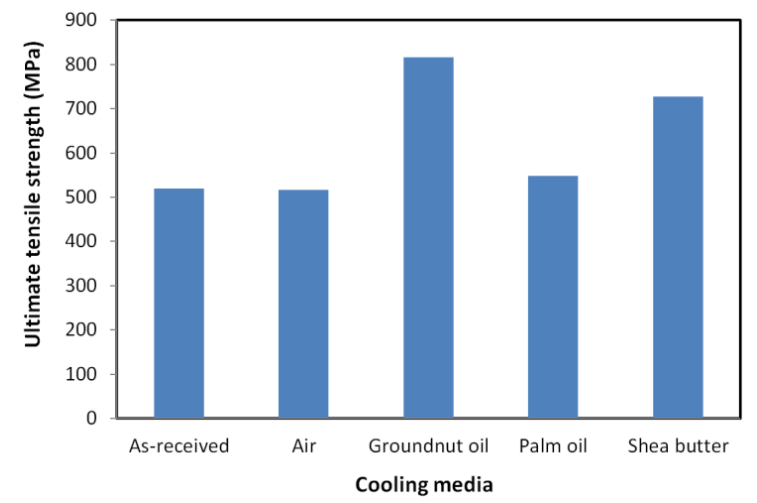

Fig. 6. Ultimate tensile strength of heat treated mild steel cooled in different cooling media.

Fig. 5 and 6 show that the specimen cooled in groundnut oil had the highest yield and ultimate tensile strengths. Its values were more than that of the as-received specimen and other specimens cooled in cooled in other coolant. This could be attributed to the cooling rate of the specimens in the media, and which is most pronounced in groundnut oil. 
From Table II and Fig.2 to 6, it was observed that influence of the cooling media ranked in ascending order as; air, palm oil, groundnut oil and shea butter with respect to the yield strength and ultimate tensile strength, taking the as-received specimen as reference. Similarly, the hardness performance increased in the order of air, palm oil, groundnut oil and shea butter, taking the as-received specimen as reference. These results are in agreement with the assertion of earlier studies that that strengths and toughness display mirror behaviours [7], [8].

In contract, the percentage elongation ranked in ascending order of; palm oil, groundnut oil, air, and shea butter. Also, the elongation was observed to have improved for air cooled compared to the as-purchased and those cooled in other media, as lower cooling rate has been reported to have a positive effect on elongation [15]. This implies that aircooled treatment proved better than treatment in other used media in terms of ductility. Generally, the results showed that heat treated mild steel cooled in these media exhibited superior mechanical properties over the original untreated specimen in terms of higher hardness, strength and percentage elongation.

\section{A. Microstructural Analysis}

Fig. 7 shows the microstructure of the as-received specimen, and specimens cooled in air, palm oil and shea butter, respectively. The microstructure of as-received specimen (Fig. 7(a)) showed a combination of ferrite (reddish) and pearlite (black), and it can be observed that the as-received specimen possessed a higher degree/presence of ferrite structures, as is common to mild steel. Furthermore, the microstructure of the specimens cooled in the media (Fig. 7(b)-(e)) showed the shape and size transformation from the original austenite grains were influenced to significant extents.

In the air cooled specimen, the pearlite was more uniformly in a finer ferrite due to the slow cooling of the specimen from the autenizing range to room temperature which had contributed to the microstructure with stress free matrix. The specimen was compensated with reduced brittleness and enhanced ductility. Sample cooled in groundnut oil shows substantial martensite structure, the fast cooling rate from the austenite temperature to room temperature gave mixture of hard microstructure of some medium carbon martensite and fewer pearlites. As a result of this microstructure which is hard, there was increase in tensile strength, hardness and reduction in ductility of the material [16].

Meanwhile, it can also be observed that the palm oil and shea butter cooled specimens (Fig. 7(d) and (e)) gave a moderate grain structure with moderate homogeneity between pearlite and martensite phases/structures. Mechanically, their strengths, hardness and ductility fall between the air cooled and groundnut oil cooled specimens.

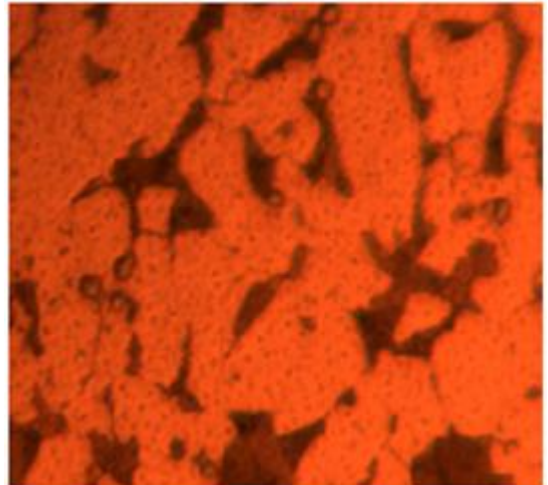

(a)

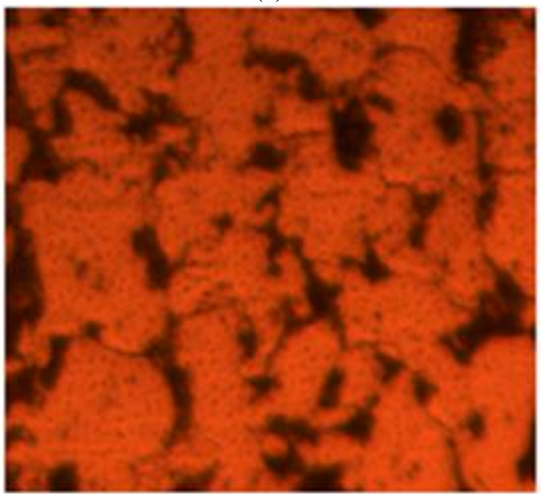

(b)

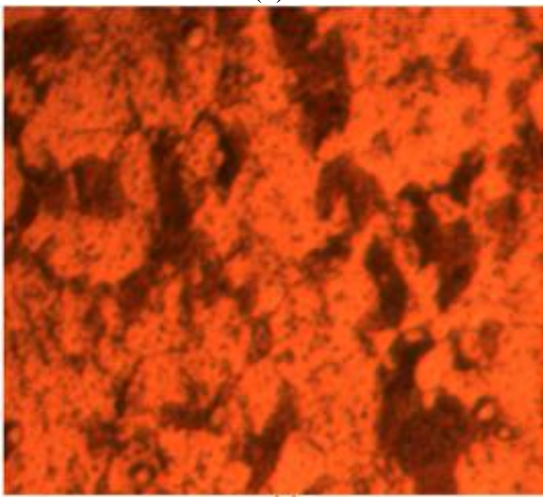

(c)

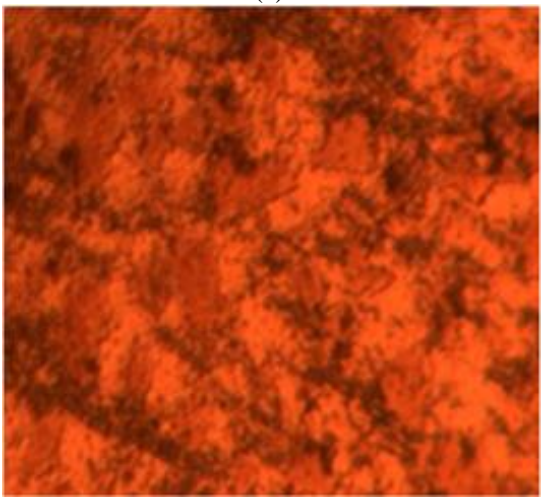

(d) 


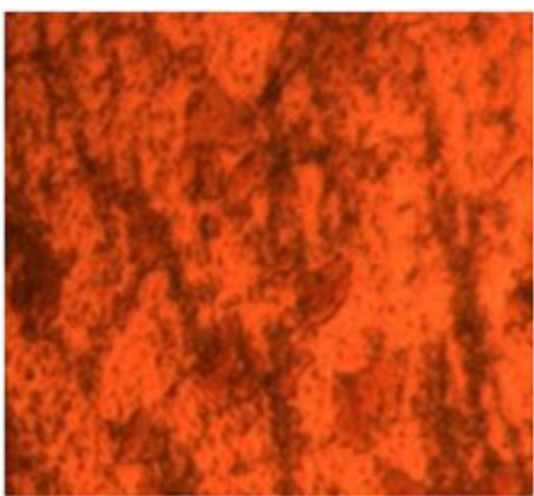

(e)

Fig. 7. Microstructure of (a) as-purchased sample, (b) air-cooled sample, (c) groundnut oil-cooled sample, (d) palm oil-cooled sample and (e) shea butter-cooled sample $(\times 500)$.

\section{CONCLUSION}

Experimental investigation was carried out on the effects of local cooling media on the mechanical properties of heat treated mild steel. The results of this work were achieved from the mechanical tests (hardness test, tensile test and microstructural analysis) carried out on the various specimens cooled in the different coolants (air, palm oil, groundnut oil and shea butter), and the mechanical properties of the as-received specimens served as reference in the discussion. The results of the experimental tests carried out showed that:

- cooling the heated mild steel in the different media used have varying effects on mechanical properties and microstructure of the mild steel.

- the air-cooled specimen had the lowest hardness number but highest percentage of elongation when compared to the specimens cooled in other media and the as-received specimen. Hence, air-cooled should be considered in applications of mild steel that require a high ductility.

- the groundnut-oil cooled specimen was observed to possess higher yield and ultimate tensile strength than the other specimens tested. Thus, it is recommended applications aimed at improving the tensile strength or toughness of mild steel.

- the groundnut cooled specimen was observed to have a finer grain structure when compared to other specimen. Thus, groundnut oil is recommended for use for an improved microstructure.

\section{REFERENCES}

[1] Smith, W.F. and J. Hashemi, Foundations of materials science and engineering. 2011: McGraw-Hill.

[2] John, V.B., Introduction to Engineering Materials. 2nd ed. 1980: Macmillan Publishing Company Ltd.

[3] Rajan, T., A. Sharma, and C. Sharma, Heat treatment: Principles and techniques. 2011: PHI Learning Pvt. Ltd.

[4] Fadare, D., T. Fadara, and O. Akanbi, Effect of heat treatment on mechanical properties and microstructure of NST 37-2 steel. Journal of Minerals and Materials Characterization and Engineering, 2011. 10(03): p. 299.

[5] Adebayo, A. and J. Stephen, Effects of Heat Treatment on the Mechanical Properties of Mild Steel. Journal of Applied Sciences, 2008. 3(3): p. 162-166.

[6] Hasan, M.F., Analysis of Mechanical Behavior and Microstructural Characteristics Change of ASTM A-36 Steel Applying Various Heat Treatment. Journal of Material Science \& Engineering, 2016. 5(2): p. 1-6.
[7] Offor, P., C. Daniel-Mkpume, and D. Obikwelu, Effects of Various Quenching Media on the Mechanical Properties of Intercritically Annealed $0.15 w t \%$ C-0.43 wt\% Mn Steel. Nigerian Journal of Technology, 2010. 29(2): p. 76-81.

[8] Ahaneku, I., A. Kamal, and O. Ogunjirin, Effects of Heat Treatment on the Properties of Mild Steel Using Different Quenchants. Frontiers in Science, 2012. 2(6): p. 153-158.

[9] Grishin, S. and Y.N. Churyukin, Evaluation of the cooling capacity of quenching media based on water. Metal Science and Heat Treatment, 1986. 28(10): p. 744-745.

[10] Odusote, J.K., T.K. Ajiboye, and A.B. Rabiu, Evaluation of mechanical properties of medium carbon steel quenched in water and oil. AU Journal of Technology, 2012. 15(4).

[11] Tolstousov, A. and O. Bannykh, New quenching media based on water-soluble polymers. Metal Science and Heat Treatment, 1981. 23(2): p. 104-106.

[12. Jumare, A., S. Aku, F. Anafi, and R. Suleman, Assessment of mechanical properties of mild steel drawn using vegetable fatty-based oils as lubricants. Global Journal of Pure and Applied Sciences, 2011. 17(1): p. 99-107.

[13] Adeyemi, G., J.T. Stephen, and O.D. Akindele, Effects of Coolants on the Welding Zone of Mild Steel Rods In Corrosive Media. 2013.

[14] Adekunle, A., K. Adebiyi, and M. Durowoju, Impact of quench severity and hardness on aisi 4137 using eco-friendly quenchants as industrial heat treatment. Journal of Mechanical Engineering and Sciences, 2013. 4: p. 409-417.

[15] GÜndÜz, S. and A. Çapar, Influence of forging and cooling rate on microstructure and properties of medium carbon microalloy forging steel. Journal of Materials Science, 2006. 41(2): p. 561-564.

[16] Dempsey, J., Quenchants: air, brine, water, oil, synthetics and super quench, FQAs webboard on quenchants in internet resource for blacksmith. 2012.

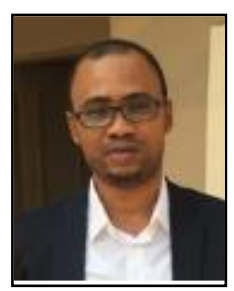

Adebayo, Adeyinka is a native of Ado-Ekiti, Nigeria. He obtained Bachelor of Engineering in Mechanical Engineering, University of Ado-Ekiti, Ado-Ekiti, Nigeria, (1999), Masters of Science in Mechanical Engineering, University of Ibadan, Ibadan, Nigeria, (2005), and $\mathrm{PhD}$ in Mechanical Engineering, University of Cranfield, UK, (2014).

$\mathrm{He}$ is lecturer in the Department of Mechanical Engineering, Faculty of Engineering, Ekiti State University, Ado-Ekiti. His areas of specialisation are material and manufacturing process. Dr. Adebayo is a corporate member of Nigeria Society of Engineer and registered Engineer with Council for the Regulation of Engineering in Nigeria.

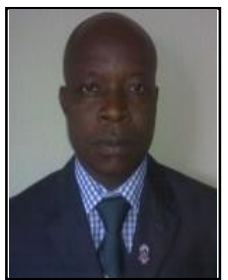

Stephen, Joseph Temitope is a native of Ado-Ekiti, Nigeria. He obtained Bachelor of Engineering in Mechanical Engineering, University of Ado-Ekiti, Ado-Ekiti, Nigeria, (1997), Masters of Science in Mechanical Engineering, University of Ibadan, Ibadan, Nigeria, (2005), and $\mathrm{PhD}$ in Mechanical Engineering, The University of Sheffield, United Kingdom, (2015)

$\mathrm{He}$ is lecturer in the Department of Mechanical Engineering, Faculty of Engineering, Ekiti State University, Ado-Ekiti. His areas of specialisation are design, material and triboacoustic. Dr. Stephen is a corporate member of Nigeria Society of Engineer, corporate member Nigerian Institution of Mechanical Engineers and registered Engineer with Council for the Regulation of Engineering in Nigeria.

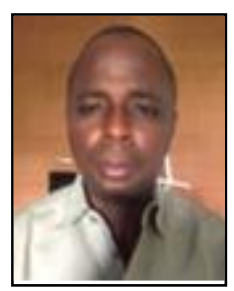

Adeyemi Gbenga Joshua was born in Ado-Ekiti, Nigeria. He obtained Post Diploma in Mechanical Engineering, University of Ado-Ekiti, Ado-Ekiti, Nigeria, (2002), Masters of Engineering in Mechanical Engineering, University of Ado-Ekiti, Ado-Ekiti, Nigeria, (2009) and PhD in Mechanical Engineering, The University of Sheffield, United Kingdom, (2018).

$\mathrm{He}$ is presently a lecturer in the Department of Mechanical Engineering, Faculty of Engineering, Ekiti State University, Ado-Ekiti. His areas of specialisation are material and triboacoustic. Dr. Adeyemi is a corporate member of Nigeria Society of Engineer, corporate member Nigerian Institution of Mechanical Engineers and registered Engineer with Council for the Regulation of Engineering in Nigeria. 